\title{
Chiral Separation by Electrokinetic Capillary Chromatography Using Newly Synthesized Linear Polymers Containing L-Amino Acid Moieties
}

\author{
Masaki HAMADA and Akira DOBASHI ${ }^{\dagger}$ \\ Tokyo University of Pharmacy and Life Science, School of Pharmacy, 1432-1, Horinouchi, \\ Hachioji, Tokyo 192-0392, Japan
}

\begin{abstract}
Chiral linear polymers were prepared by the thermal polymerization of $N$-acryloyl-L-valine and $N$-acryloyl-L-alanine derivatives using 3-mercaptopropionic acid (3-MPA) as a radical transfer agent. C-Terminal groups of the derivatives were methyl and tert-butyl esters later removed, and $N$-methylamide moieties. The $N^{\prime}$-methylamide derivative of $N$ acryloyl-L-valine was copolymerized with its methyl ester at a molar mixing ratio of 1:1. The ester groups were removed to provide anionic linear polymers terminated with carboxylic acid of the amino acid residue. The polymers are thus shown to function as pesudostationary phases that separate enantiomeric solutes in electrokinetic capillary chromatography (EKC). Racemic 3,5-dinitrobenzoylamino isopropyl esters were separated with the polymer derived from $N$-acryloyl-L-valine esters and with the copolymer from $N$-acryloyl-L-valine methyl ester and $N$-acryloyl-L-valine $N^{\prime}$-methylamide at $\mathrm{pH}$ 7.0. These separations could not be observed at $\mathrm{pH} 9.0$ in migrating solutions containing anionic linear polymers. This $\mathrm{pH}$ dependence can be discussed from the standpoint of the microscopic hydrophobicity of the polymers, as assessed from the fluorescence of pyrene adsorbed onto the polymers in water.
\end{abstract}

(Received November 14, 2001; Accepted December 4, 2001)

\section{Introduction}

Electrokinetic capillary chromatography (EKC) is an advanced technique for determining whether ionic macromolecules, in which solutes are distributed from the bulk aqueous phase, undergo separation. ${ }^{1,2}$ Micelles formed spontaneously by ionic surfactants $^{3,4}$ and ionic micelle-like polymers ${ }^{5-8}$ function as well as pseudostationary phases in EKC. The solute retentivity and separability in macromolecules may be explained as being due to the formation of hydrophobic interior regions and the solute distribution within these regions. ${ }^{9-11}$

In the present study, chiral linear polymers derived from $\mathrm{N}$ acryloyl-L-amino acid derivatives were found to aggregate in aqueous solution, and the polymers to enantioselectively take in racemic amino acid derivatives during the EKC separation process. Various chiral polymers have been prepared by the thermal telomerization of $N$-acryloyl-L-valine and $N$-acryloyl-Lalanine derivatives using 3-mercaptopropionic acid (3-MPA) as a radical transfer agent. ${ }^{12}$ For two series of polymers, the derivatives used were methyl and tert-butyl esters to obtain carboxylic acid, which was subsequently cleaved, with $\mathrm{N}$ methylamide presumably remaining in the polymer. Amino acid residues of polymers are lined up repeatedly on straight carbon backbones formed by the polymerization of acryloyl groups, as is apparent from Fig. 1. The elongation of a monomer that determines the molecular weights of the resulting polymers was controlled by mixing the ratios of the amino acid derivatives to 3-MPA. Removal of the ester groups from both types of unimolecular polymers and copolymers rendered them

$\doteqdot$ To whom correspondence should be addressed.

E-mail: dobashi@ps.toyaku.ac.jp water-soluble. Dissociation in the carboxylic acid present in the residues should change according to the $\mathrm{pH}$ of the migrating solution, and thus aggregation of the polymers that permits enantiomer absorption may be controlled by electric repulsion between these functional groups. The $\mathrm{pH}$ dependence is discussed based on the microscopic hydrophobicity, as assessed from the fluorescence of pyrene adsorbed onto the polymers in water.

\section{Experimental}

EKC was conducted using a Model 270A capillary electrophoresis system (PE Applied Biosystems, Tokyo, Japan). Chromatography was carried out at $25^{\circ} \mathrm{C}$ using fused-silica tubing $(50 \mu \mathrm{m}$ i.d. $\times 70 \mathrm{~cm}, 50 \mathrm{~cm}$ effective length; PE Applied Biosystems). Methanol was used as the sample solvent, and the sample solution was injected hydrodynamically into a capillary over a period of $0.2 \mathrm{~s}$. The polymer hydrophobicity was determined from the intensity ratio of the pyrene emission peak at $383 \mathrm{~nm}\left(I_{383}\right)$ relative to that at $373 \mathrm{~nm}\left(I_{373}\right)\left(I_{383} / I_{373}\right)$ in a 2.0 $\mathrm{w} / \mathrm{v} \%$ aqueous solution saturated with pyrene. Pyrene was excited at $337 \mathrm{~nm}$ and its fluorescence spectrum was measured with a fluorospectrophotometer (FP-777; JASCO, Tokyo, Japan) at $25^{\circ} \mathrm{C} .{ }^{12}$ A ${ }^{1} \mathrm{H}-\mathrm{NMR}$ measurement was made using a Varian Gemini-300 (300 MHz NMR). The internal standard was chloroform (7.26 ppm) in a deuteriochloroform solution.

Preparation of $\mathrm{N}$-acryloyl-L-alanine methyl ester (monomer 1), $\mathrm{N}$-acryloyl-L-valine methyl ester (monomer $2 a$ ) and $\mathrm{N}$-acryloylL-valine tert-butyl ester (monomer $\mathbf{2 b}$ )

The starting materials for obtaining $N$-acryloyl derivatives were the methyl and tert-butyl ester hydrochlorides of L-valine 


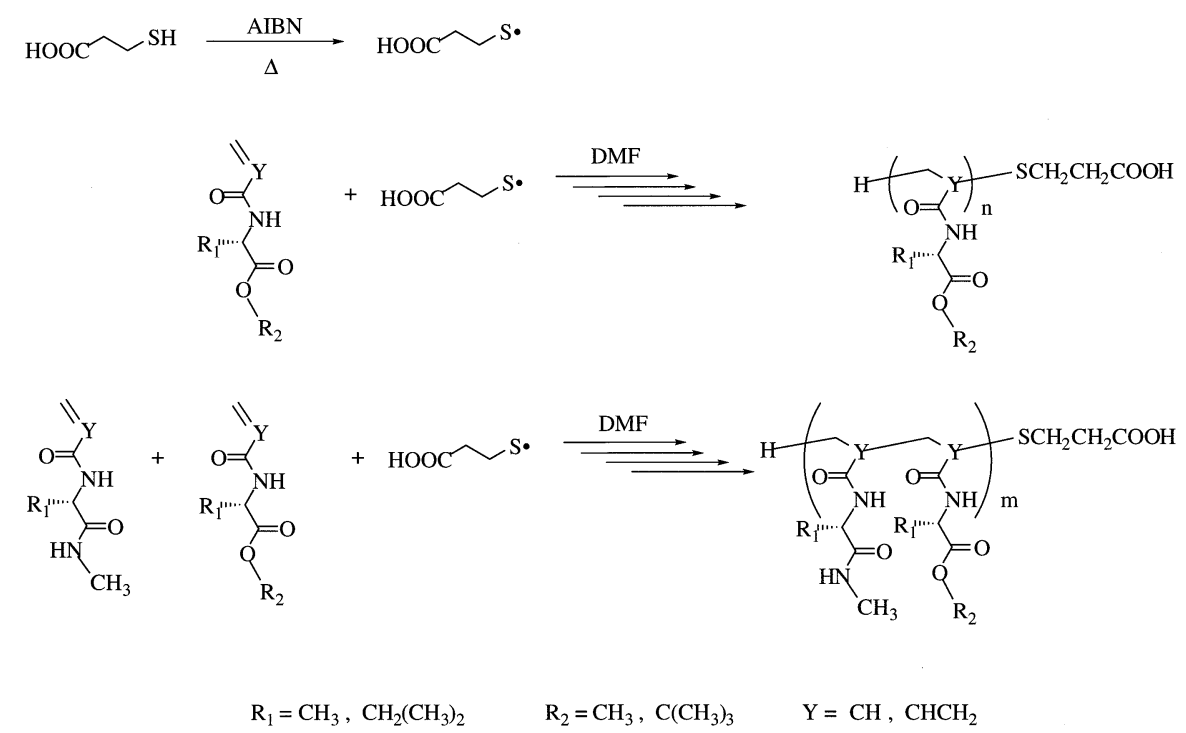

Fig. 1 Synthetic schemes and structures of chiral linear polymers derived from $N$-acryloyl- and $N$ vinylacetyl-L-amino acid derivatives.

and L-alanine. The $N$-acryloyl-L-valine methyl ester (monomer 2a) was obtained according to the following process.

L-Valine methyl ester hydrochloride (11.73 g) was dissolved in $100 \mathrm{ml}$ of chloroform and placed in an ice-water bath, followed by the addition of trimethylamine $(22.3 \mathrm{ml})$ and then acryloyl chloride $(6.1 \mathrm{ml})$. After stirring for $4 \mathrm{~h}$, the reaction mixture was washed with $100 \mathrm{ml}$ of water, $100 \mathrm{ml}$ of $5 \% \mathrm{HCl}$ twice and $100 \mathrm{ml}$ of saturated $\mathrm{NaCl}$, and then dried over anhydrous $\mathrm{Na}_{2} \mathrm{SO}_{4}$. The solvent was removed under reduced pressure and the residue purified by silica-gel chromatography with ethyl acetate as the eluent. The combined fractions were evaporated to dryness, to afford $7.09 \mathrm{~g}(54.7 \%$ yield $)$ of the desired material: ${ }^{1} \mathrm{H}-\mathrm{NMR}\left(\mathrm{CDCl}_{3}\right) \delta 0.87(\mathrm{~d}, 3 \mathrm{H}, J=6.6 \mathrm{~Hz})$, $0.94(\mathrm{~d}, 3 \mathrm{H}, J=6.5 \mathrm{~Hz}), 2.20-2.40(\mathrm{~m}, 1 \mathrm{H}), 3.34$ (s, 3H), 4.91 $(\mathrm{dd}, 1 \mathrm{H}, J=6.5,9.0 \mathrm{~Hz}), 5.65(\mathrm{dd}, 1 \mathrm{H}, J=1.8,10.0 \mathrm{~Hz}), 6.15$ $(\mathrm{dd}, 1 \mathrm{H}, J=10.0,17.1 \mathrm{~Hz}), 6.39(\mathrm{dd}, 1 \mathrm{H}, J=1.8,17.1 \mathrm{~Hz})$, $6.68-6.80($ brs, $1 \mathrm{H}),[\alpha]_{\mathrm{D}}^{25}=-42.38^{\circ}(c=1.01$, methanol).

The following other derivatives were identified:

$N$-Acryloyl-L-alanine methyl ester (monomer 1): ${ }^{1} \mathrm{H}-\mathrm{NMR}$ $\left(\mathrm{CDCl}_{3}\right) \delta 1.41(\mathrm{~d}, 3 \mathrm{H}, J=6.9 \mathrm{~Hz}), 5.69(\mathrm{dd}, 1 \mathrm{H}, J=1.5,10$ $\mathrm{Hz}), 6.15-6.25$ (brs, 1H), 6.11 (dd, 1H, $J=10.0,17.0 \mathrm{~Hz}), 6.31$ $(\mathrm{dd}, 1 \mathrm{H}, J=1.4,17.3 \mathrm{~Hz}) ;[\alpha]_{\mathrm{D}}^{25}=-35.02^{\circ}(c=1.00$, methanol). $N$-Acryloyl-L-valine tert-butyl ester (monomer $2 \mathbf{b}$ ): ${ }^{1} \mathrm{H}-\mathrm{NMR}$ $\left(\mathrm{CDCl}_{3}\right) \delta 0.87(\mathrm{~d}, 3 \mathrm{H}, J=6.5 \mathrm{~Hz}), 0.92(\mathrm{~d}, 3 \mathrm{H}, J=6.5 \mathrm{~Hz})$, $1.48(\mathrm{~s}, 9 \mathrm{H}), 2.08-2.18(\mathrm{~m}, 1 \mathrm{H}), 4.45(\mathrm{dd}, 1 \mathrm{H}, J=6.0,6.4 \mathrm{~Hz})$, $5.12-5.28(\mathrm{~m}, 2 \mathrm{H}), 5.81-6.01(\mathrm{~m}, 1 \mathrm{H}), 7.03-7.15(\mathrm{~m}, 1 \mathrm{H})$; $[\alpha]_{\mathrm{D}}^{25}=-51.20^{\circ}(c=1.02$, methanol $)$.

Preparation of $N$-vinylacetyl-L-valine methyl ester (monomer 3 ) $\mathrm{N}$-Vinylacetyl-L-amino methyl ester was prepared from Lamino methyl ester hydrochloride and vinylacetic acid using $N$ ethoxycarbonyl-2-ethoxy-1,2-dihydroquinoline (EEDQ) as the coupling reagent in a methanol/benzene $(1: 1(\mathrm{v} / \mathrm{v}))$ mixture. The typical synthesis of $N$-vinylacetyl-L-valine methyl ester (monomer 3) was carried out according to the following process.

L-Valine methyl ester hydrochloride $(17.9 \mathrm{~g})$ was dissolved in $120 \mathrm{ml}$ of methanol/benzene $(1: 1(\mathrm{v} / \mathrm{v}))$ and placed in an icewater bath. Vinylacetic acid (8.99 ml), EEDQ (26.5 g) and then trimethylamine $(14.8 \mathrm{ml})$ were added to the mixture, followed by stirring for $24 \mathrm{~h}$. The solvent was evaporated and $100 \mathrm{ml}$ chloroform was added to the residue. This mixture was washed with $100 \mathrm{ml}$ of water, $100 \mathrm{ml}$ of $10 \% \mathrm{HCl}$ twice and $100 \mathrm{ml}$ of saturated $\mathrm{NaCl}$, and then dried over anhydrous $\mathrm{Na}_{2} \mathrm{SO}_{4}$. The solvent was removed under reduced pressure and the residue was eluted from by silica gel using ethyl acetate-hexane (1:10 $(\mathrm{v} / \mathrm{v}))$. The combined fractions were evaporated to dryness to produce $14.16 \mathrm{~g}$ (66.5\% yield) of the desired material: ${ }^{1} \mathrm{H}-\mathrm{NMR}$ $\left(\mathrm{CDCl}_{3}\right) \delta 0.96(\mathrm{~d}, 6 \mathrm{H}, J=6.7 \mathrm{~Hz}), 2.02-2.19(\mathrm{~m}, 1 \mathrm{H}), 4.81-$ $4.89(\mathrm{~m}, 1 \mathrm{H}), 5.13(\mathrm{~s}, 2 \mathrm{H}), 5.69(\mathrm{dd}, 1 \mathrm{H}, J=1.6,10.1 \mathrm{~Hz}), 5.82$ -5.95 (brs, 1H), $6.12(\mathrm{dd}, 1 \mathrm{H}, J=10.1,17.0 \mathrm{~Hz}), 6.29(\mathrm{dd}, 1 \mathrm{H}$, $J=1.6,17.0 \mathrm{~Hz}) .[\alpha]_{\mathrm{D}}^{25}=-46.20^{\circ}(c=1.01$, methanol $)$.

Preparation of $N$-acryloyl-L-valine $N^{\prime}$-methylamide (monomer 4 ) and $N$-vinylacetyl-L-valine $N^{\prime}$-methylamide (monomer 5)

$N$-acryloyl-L-valine $N^{\prime}$-methylamide (monomer 4) was obtained in the following manner.

$N$-Benzyloxycarbonyl(Z)-L-valine $\quad N$-hydroxysuccinimide ester was prepared at this laboratory $\left(24.39 \mathrm{~g}\right.$; mp $\left.118-119^{\circ} \mathrm{C}\right)$ based on previously described synthetic procedures. ${ }^{14}$ The ester and methylamine hydrochloride $(5.2 \mathrm{~g})$ were dissolved in 250 $\mathrm{ml}$ of chloroform and placed in an ice-water bath. Triethylamine $(25 \mathrm{ml})$ was added and the mixture was stirred for $5 \mathrm{~h}$. This was followed by washing with $100 \mathrm{ml}$ of $1 \mathrm{M} \mathrm{HCl}, 100 \mathrm{ml}$ of $1 \mathrm{M}$ $\mathrm{NaOH}$ and $100 \mathrm{ml}$ of saturated $\mathrm{NaCl}$, drying over anhydrous $\mathrm{Na}_{2} \mathrm{SO}_{4}$ and finally evaporation to dryness under reduced pressure. The residue was recrystallized from ethyl acetate-hexane to give $57.36 \mathrm{~g}$ of the desired material $(\mathrm{N}-\mathrm{Z}$ valine $N^{\prime}$-methylamide): mp $180-181^{\circ} \mathrm{C} ;{ }^{1} \mathrm{H}$-NMR $\left(\mathrm{CDC1}_{3}\right) \delta$ $0.87(\mathrm{~d}, 3 \mathrm{H}, J=6.6 \mathrm{~Hz}), 0.94(\mathrm{~d}, 3 \mathrm{H}, J=6.5 \mathrm{~Hz}), 2.20-2.40$ (m, 1H), $2.77(\mathrm{~d}, 3 \mathrm{H}, J=4.9 \mathrm{~Hz}), 2.91(\mathrm{~s}, 3 \mathrm{H}), 4.02(\mathrm{~d}, 1 \mathrm{H}, J=$ $11.3 \mathrm{~Hz}), 5.15(\mathrm{~s}, 2 \mathrm{H}), 5.80-5.88$ (brd, 1H), 0.93 (brs, 1H), $7.32-7.39(\mathrm{~m}, 5 \mathrm{H})$

To a solution of $N$-Z-valine $N^{\prime}$-methylamide $(10.75 \mathrm{~g})$ in 30 $\mathrm{ml}$ of methanol was added a catalytic amount of $5 \%$ palladiumcarbon. The mixture was hydrogenated under an atmosphere of hydrogen gas. The catalyst was removed by filtration, and from the filtrate the solvent was evaporated to dryness under reduced pressure to yield of a $5.32 \mathrm{~g}$ colorless oil, which was subsequently dissolved in $200 \mathrm{ml}$ of chloroform. To this system, acryloyl chloride $(4 \mathrm{ml})$, and then triethylamine $(8.8 \mathrm{ml})$, were added, followed by stirring in an ice-water bath for $1.5 \mathrm{~h}$ 
and then at room temperature for $15 \mathrm{~h}$. The mixture was washed with water, dried over anhydrous $\mathrm{Na}_{2} \mathrm{SO}_{4}$ and evaporated to dryness under reduced pressure. The residue was eluted through silica gel with ethyl acetate-hexane $(1: 5(\mathrm{v} / \mathrm{v}))$, and recrystallized from ethyl acetate-hexane to give $7.20 \mathrm{~g}$ of the desired material: subliming at $172^{\circ} \mathrm{C} ;{ }^{1} \mathrm{H}-\mathrm{NMR}\left(\mathrm{CDC1}_{3}\right) \delta$ $0.96(\mathrm{~d}, 6 \mathrm{H}, J=6.6 \mathrm{~Hz}), 2.04-2.19(\mathrm{~m}, 1 \mathrm{H}), 2.82(\mathrm{~d}, 3 \mathrm{H}, J=$ $4.8 \mathrm{~Hz}), 4.19-4.30(\mathrm{~m}, 1 \mathrm{H}), 5.67(\mathrm{dd}, 1 \mathrm{H}, J=1.5,10 \mathrm{~Hz}), 5.83$ - 5.95 (brs, $1 \mathrm{H}$ ), 6.13 (dd, $1 \mathrm{H}, J=10,16.9 \mathrm{~Hz}$ ), 6.10 - 6.24 (brs, $1 \mathrm{H}), 6.30(\mathrm{dd}, 1 \mathrm{H}, J=1.5,16.9 \mathrm{~Hz}) ;[\alpha]_{\mathrm{D}}^{25}=-75.91^{\circ}(c=1.00$, methanol).

The synthesis of $N$-vinylacetyl-L-valine $N^{\prime}$-methylamide (monomer 5) was conducted as similar procedures described above using the $N^{\prime}$-methylamide derivative: ${ }^{1} \mathrm{H}-\mathrm{NMR}\left(\mathrm{CDCl}_{3}\right) \delta$ $0.96(\mathrm{~d}, 6 \mathrm{H}, J=6.7 \mathrm{~Hz}), 2.05-2.20(\mathrm{~m}, 1 \mathrm{H}), 2.83(\mathrm{~d}, 3 \mathrm{H}, J=$ $4.9 \mathrm{~Hz}), 4.24$ (dd, 1H, J = 7.3, 8.9 Hz), 5.13 (s, 2H), 5.69 (dd, $1 \mathrm{H}, J=1.6,10.1 \mathrm{~Hz}), 5.85-5.93$ (brs, $1 \mathrm{H}), 6.12$ (dd, $1 \mathrm{H}, J=$ $10.1,17.0 \mathrm{~Hz}), 6.10-6.25$ (brs, $1 \mathrm{H}), 6.29$ (dd, $1 \mathrm{H}, J=1.6,17.0$ Hz). $[\alpha]_{\mathrm{D}}^{25}=-76.21^{\circ}(c=1.03$, methanol $)$.

Thermal telomerization of amino acid derivatives in the presence of 3-MPA

$N$-Acryloyl-L-amino acid derivatives and $N$-vinylacetyl-Lvaline methyl ester were heat-polymerized with 3-MPA as the chain transfer agent and 2,2'-azobisisobutyronitrile (AIBN) as a radical initiator.

Poly( $N$-acryloyl-L-valine methyl ester) (carboxyl groupprotected polymer $\mathbf{2 a}$ ) was typically obtained as follows.

To a solution of $N$-acryloyl-L-valine methyl ester $(9.31 \mathrm{~g})$ in $120 \mathrm{ml}$ of DMF were added 3-MPA (106 mg) and AIBN (82 $\mathrm{mg}$ ). After degassing by bubbling argon for $20 \mathrm{~min}$ in an icewater bath, the mixture was heated at $80^{\circ} \mathrm{C}$ for $16 \mathrm{~h}$ under argon with stirring. The product was evaporated to dryness under reduced pressure and the residual oil was eluted by silica gel using ethyl acetate. Colored impurities were removed by adsorption onto activated charcoal in methanol and by filtration. The filtrate was evaporated to dryness to produce an oily residue of $6.7 \mathrm{~g}$ (72\% yield).

Cleavage of ester groups from polymers obtained by telomerization

The procedure for obtaining poly $(N$-acryloyl-L-valine methyl ester) was as follows.

First, $20 \mathrm{ml} \mathrm{KOH-methanol} \mathrm{containing} 0.56 \mathrm{~g}$ of $\mathrm{KOH}$ and 10 $\%(\mathrm{v} / \mathrm{v})$ water were added into a solution of poly $(\mathrm{N}$-acryloyl-Lvaline methyl ester) $(1.46 \mathrm{~g})$ in $80 \mathrm{ml}$ of methanol. The mixture was stored at room temperature for $15 \mathrm{~h} ; 1.20 \mathrm{ml}$ of $70 \% \mathrm{HClO}_{4}$ was then added with cooling in an ice-water bath. Following removal of the $\mathrm{KClO}_{4}$ precipitate, the filtrate was evaporated to dryness under reduced pressure, the residue was dissolved in 10 $\mathrm{ml}$ of methanol, and $100 \mathrm{ml}$ of diethyl ether was added to the mixture. The precipitate was thoroughly washed with diethyl ether and dried under reduced pressure. The desired product obtained was $0.91 \mathrm{~g}$ of white powder.

Poly $(N$-acryloyl-L-valine tert-butyl ester) (carboxyl groupprotected polymer $\mathbf{2 b}$ ) was made by the following procedure,

Poly( $N$-acryloyl-L-valine tert-butyl ester) $(1.51 \mathrm{~g})$ was dissolved in $10 \mathrm{ml}$ of trifluoroacetic acid (TFA) with stirring, and left to stand at room temperature for $48 \mathrm{~h}$. The solvent was evaporated to dryness under reduced pressure. The residue was dissolved into a mixture of chloroform and methanol. Next, the solvent was removed again by evaporation. The residue was dissolved in $5 \mathrm{ml}$ of methanol and mixed with $100 \mathrm{ml}$ of diethyl ether. The precipitate was thoroughly washed with diethyl ether and dried under reduced pressure to produce the desired product
Table 1 Average molecular weight $(\mathrm{Mw})$, polydispersity $(\mathrm{Mw} / \mathrm{Mn})$ and degree of polymerization $(N)$ of chiral polymers protected as the esters ${ }^{\mathrm{a}}$

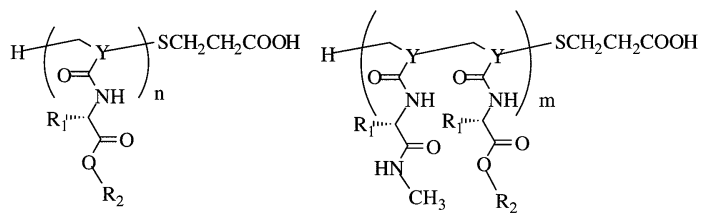

\begin{tabular}{ccccccccc}
\hline $\begin{array}{c}\text { Protected } \\
\text { polymer }\end{array}$ & $\mathrm{R}_{1}$ & $\mathrm{R}_{2}$ & $\mathrm{Y}$ & Monomer $^{\mathrm{b}}$ & $\mathrm{Mw}$ & $\mathrm{Mw} / \mathrm{Mn}$ & $N$ \\
\hline $\mathbf{1}$ & $\mathrm{CH}_{3}$ & $\mathrm{CH}_{3}$ & $\mathrm{CH}-$ & $\mathbf{1}$ & 28000 & 1.87 & 180 \\
$\mathbf{2 a}$ & $\mathrm{CH}\left(\mathrm{CH}_{3}\right)_{2}$ & $\mathrm{CH}_{3}$ & $\mathrm{CH}-$ & $\mathbf{2 a}$ & 22000 & 1.69 & 108 \\
$\mathbf{2 b}$ & $\mathrm{CH}\left(\mathrm{CH}_{3}\right)_{2}$ & $\mathrm{C}\left(\mathrm{CH}_{3}\right)_{3}$ & $\mathrm{CH}-$ & $\mathbf{2 b}$ & 20000 & 1.18 & 98 \\
$\mathbf{3}$ & $\mathrm{CH}^{2}\left(\mathrm{CH}_{3}\right)_{2}$ & $\mathrm{CH}_{3}$ & $\mathrm{CHCH}_{2-}$ & $\mathbf{3}$ & 16000 & 1.61 & 84 \\
$(\mathbf{2 a}, \mathbf{4})^{c}$ & $\mathrm{CH}\left(\mathrm{CH}_{3}\right)_{2}$ & $\mathrm{CH}_{3}$ & $\mathrm{CH}_{-}$ & $\mathbf{2 a , 4}$ & 19000 & 1.36 & 105 \\
$(\mathbf{3 , 5})^{c}$ & $\mathrm{CH}\left(\mathrm{CH}_{3}\right)_{2}$ & $\mathrm{CH}_{3}$ & $\mathrm{CHCH}_{2-}$ & $\mathbf{3 , 5}$ & 15000 & 1.50 & 74 \\
\hline
\end{tabular}

a. Mw and Mw/Mn were measured with GPC (see Experimental section).

b. $R_{1}, R_{2}$ and $Y$ are substituents in chiral linear polymers illustrated in Fig. 1.

c. Molar ratio $(o / p)$ of two monomers in protected polymer $(\mathbf{2 a}, \mathbf{4})$ and $(3,5)$ were determined by ${ }^{1} \mathrm{H}-\mathrm{NMR}$ based on the ratio of integration intensity of methyl groups in C-terminal $\mathrm{N}$-methylamide $(o)$ to that in methyl ester $(p)$ for protected polymers: $o / p$ for protected polymer $(\mathbf{2 a}, \mathbf{4})$ was 1.2 and $o / p$ of protected polymer $(\mathbf{3}, \mathbf{5})$ was 1.1 .

as $0.85 \mathrm{~g}$ of white powder.

\section{Preparation of a UV-labeled polymer}

Poly $(N$-acryloyl-L-valine tert-butyl ester) $(3.89$ g) was dissolved in $30 \mathrm{ml}$ of tetrahydrofuran, and to this solution, $p$ aminoazobenzene $(42.6 \mathrm{mg}$ ) and EEDQ $(53.4 \mathrm{mg}$ ) were added. After stirring for $24 \mathrm{~h}$, the solvent was removed under reduced pressure and the residue was purified by silica gel chromatography with chloroform as the eluent. The combined fractions were evaporated to dryness, to afford $1.55 \mathrm{~g}$ (39\% yield) of the desired material. The assignment of the UVlabeled polymer was made with ${ }^{1} \mathrm{H}-\mathrm{NMR}$, based on proton signals in the azobenzene group: ${ }^{1} \mathrm{H}-\mathrm{NMR}\left(\mathrm{CDCl}_{3}\right) \delta 7.50-7.90$ $(\mathrm{m}, 9 \mathrm{H})$.

\section{Polymer molecular weight determination by gel permeation chromatography $(G P C)$}

The average molecular weight $(\mathrm{Mw})$ of the polymer and the molecular-weight distribution $(\mathrm{Mw} / \mathrm{Mn})$ were determined by GPC using polystyrene as a molecular-weight calibration standard $\left(\mathrm{Mw}=5.0 \times 10^{2}-1.06 \times 10^{6}\right)($ column, TOSOH TSKGEL GMHHR-M (0.78 i.d. $\times 30 \mathrm{~cm})$; eluent, DMF; flow rate, $0.5 \mathrm{ml} / \mathrm{min}$; column temperature, $40^{\circ} \mathrm{C}$ ). The results are shown in Table 1 .

\section{Preparation of migrating solution in EKC}

A buffer solution for EKC was prepared by mixing $0.025 \mathrm{M}$ $\mathrm{Na}_{2} \mathrm{~B}_{4} \mathrm{O}_{7}$ and $0.05 \mathrm{M} \mathrm{NaH}_{2} \mathrm{PO}_{4}$ to obtain $\mathrm{pH}$ values of 7.0 and 9.0. After the polymer was dissolved in the phosphate-borate buffer, a $\mathrm{pH}$ adjustment was made with a $1 \mathrm{M} \mathrm{NaOH}$ solution. The solubility of the deprotected polymer was estimated for the phosphate-borate buffers; the polymers dissolved at room temperature were subsequently used for EKC. 


\section{Results and Discussion}

Synthesized linear polymers containing L-amino acid moieties Two chiral monomer series were prepared from L-alanine and L-valine, acylated by acryloyl or vinylacetyl groups and protected by methyl or tert-butyl esters. The acyl groups constituted the carbon chain by which the amino acid moiety was grafted onto the polymer backbone after polymerization, which would contribute to the formation of a hydrophobic environment. In water, the length of this spacer would determine the solubility and hydrophobic aggregation properties of the polymers containing terminal carboxylic acids in water.

Copolymers containing $\mathrm{N}$-methylamide, instead of being comprised of nearly half of the C-terminal carboxylic acids, would likely express a greater hydrogen-bonding affinity toward enantiomers than that containing only the bare valine moieties. These copolymers consisted of equimolar amounts of methyl ester and $N$-methylamide derived from $N$-acryloyl-Lvaline or $N$-vinylacetyl-L-valine. All of the polymers prepared in this study possessed one terminal carboxylic acid that had originated in 3-MPA as a chain transfer agent. Linear and homogeneous structures of the chain were determined by the total amount of the monomers relative to 3-MPA. The molar ratio of the monomer to 3-MPA was set at 60 .

The average molecular weight $(\mathrm{Mw})$ and polydispersity $(\mathrm{Mw} / \mathrm{Mn})$, an indicator of the molecular distribution of the polymers, were estimated by gel permeation chromatography (GPC) prior to cleavage of the ester groups, as shown in Table 1 , in that the column absorption of deprotected polymers was quite strong, possibly due to the presence of carboxylic acid moieties. The $\mathrm{Mw} / \mathrm{Mn}$ values ranged from 1.9 to 1.2 , indicating a narrower molecular distribution than for ordinary thermal polymerization without a chain transfer agent. Table 1 shows the polymerization $(N)$ calculated from the $\mathrm{Mw}$ to be 180 for the $N$-acryloyl-L-alanine methyl ester (monomer 1), and a value exceeding that for the corresponding L-valine derivative (monomer 2a), possibly since the methyl group of the alanine residue is smaller and sterically hinders elongation process to a lesser extent than the valine residue isopropyl group. A decrease in $\mathrm{Mw}$ due to the steric bulkiness of the monomers occurred in the protected polymer derived from $\mathrm{N}$-acryloyl-Lvaline tert-butyl ester (monomer $\mathbf{2 b}$ ), compared to monomer $\mathbf{2 a}$.

Copolymerization of the $N$-methylamide and methyl ester derivatives decreased the polymerization, as was evident from a comparison of polymer $\mathbf{2 a}$ with copolymer $(\mathbf{2 a}, \mathbf{4})$ and polymer $\mathbf{3}$ with copolymer $(\mathbf{3}, \mathbf{5})$, all protected as methyl esters. Even for the smallest protected copolymer $(\mathbf{3}, \mathbf{5})$, the polymerization was 74 , this possibly indicating a size sufficient to create a hydrophobic environment capable of taking in small solutes.

Since protected polymers $\mathbf{2} \mathbf{a}$ and $\mathbf{2} \mathbf{b}$ yielded the same polymer terminated with carboxylic acid after cleavage of their ester groups, this deprotected polymer is abbreviated as polymer $\mathbf{2}$.

Polymer solubility and preparation of migrating solution for EKC

The cleavage of ester groups produced polymers having terminal carboxylic acid groups. An examination was made of the polymer solubility in a phosphate-borate buffer solution with $\mathrm{pH}$ from 7.0 to 9.0. Dissolution of the terminal carboxylic acids in the polymers induced at greater buffer $\mathrm{pH}$, which should change the solubility in water and, most importantly, alter the compactness of aggregated polymers. The electrostatic repulsion between the carboxylate anions may lessen the coherent interaction between the amino acid residues with a
Table 2 Chiral separation of enantiomeric 3,5-dinitrobenzoyl (DNB) amino isopropyl esters using polymer $\mathbf{2}$ in phosphate-borate buffer ( $\mathrm{pH}$ 7.0) in electrokinetic capillary chromatography ${ }^{\mathrm{a}}$

\begin{tabular}{lcc}
\hline & $k_{\mathrm{D}}^{\prime}{ }^{\mathrm{b}}$ & $\alpha$ \\
\cline { 2 - 3 } DNB-AlaOi-Pr & 0.17 & 1.00 \\
DNB-ValOi-Pr & 0.20 & 1.10 \\
DNB-LeuOi-Pr & 0.22 & 1.13 \\
DNB-PheOi-Pr & 0.30 & 1.19 \\
\hline
\end{tabular}

a. Conditions: migrating solution, $2 \%(\mathrm{w} / \mathrm{v})$ polymer 2 in $0.05 \mathrm{M}$ phosphate-borate buffer ( $\mathrm{pH} 7.0$ ), diluted with $20 \%(\mathrm{v} / \mathrm{v})$ methanol; total applied voltage, about $-12 \mathrm{kV}$; constant electric current, $16 \mu \mathrm{A}$. Other conditions are as described in Fig. 2. Separation window denoted by $T_{\mathrm{m}} / T_{0}$ was 2.3 for $\mathrm{pH} 7.0\left(T_{0}=27.7 \mathrm{~min}, T_{\mathrm{m}}=65.0 \mathrm{~min}\right)$ and 3.5 for $\mathrm{pH} 9.0$.

b. D-Enantiomer eluted faster than L-enantiomer.

consequent interior region hydrophobicity in the polymers. Polymer $\mathbf{3}$ and copolymer $(\mathbf{3}, \mathbf{5})$, containing the vinylacetyl-Lvaline moiety, did not dissolve in the buffer at room temperature, and thus were not used in subsequent experiments. Although polymers $\mathbf{2}$ and $\mathbf{3}$ differ by the presence of only one carbon at the linkage between the L-amino acid residue and the carbon backbone, the change in solubility was still significant.

\section{Migrating velocity of polymers in EKC}

The polymers synthesized in this study were negatively charged in water due to dissociation of the terminal carboxylic acid groups. In EKC with a phosphate-borate buffer containing the polymers, the entire mixture within the column should move by electroosmotic flow toward the negative end. But a polymer, itself, is attracted electrophoretically towards the positive end. The apparent polymer migration velocity would thus be determined according to electroosmotic flow and electrophoretic migration, and would also depend on the buffer $\mathrm{pH}$. A polymer containing an azobenzene moiety was thus prepared so as to assess the dependence of the velocity on the $\mathrm{pH}$.

p-Aminoazobenzene was condensed to terminal carboxylic acid that had come from 3-MPA, in protected polymer $\mathbf{2 b}$, followed by cleavage of the tert-butyl ester with TFA. The electrophoretic behavior of the UV-labeled polymer in EKC should be quite the same as that of polymer 2 . The retention of UV-labeled polymer on a column filled with polymer 2 would reflect apparent polymer migration through the column. This would explain why an increase in the solution $\mathrm{pH}$ was noted to decrease the velocity of a polymer migrating toward the negative end.

Electroosmotic flow was determined using methanol as a neutral compound. The result was expressed as the period of time during which methanol crossed the column toward the negative end $\left(T_{0}\right)$. The ratio of this time for a UV-labeled polymer $\left(T_{\mathrm{m}}\right)$ to $T_{0}$ was 2.3 when polymer 2 was present in the migrating solution at $\mathrm{pH}$ 7.0. The anionic linear polymer prepared in this study moved slowly compared to the neutral compound in $\mathrm{EKC}$, and thus may function as a pseudostationary phase that retains solutes.

The migrating solution composition was adjusted for the enantiomeric separation of various 3,5-dinitorobenzoyl (DNB) amino isopropyl esters. The polymer concentration was made to $4 \%(\mathrm{w} / \mathrm{v})$ to ensure adequate retention, but only a slight solute retention was observed. Methanol was thus added to the migrating solution to the limit electroosmotic flow and to 


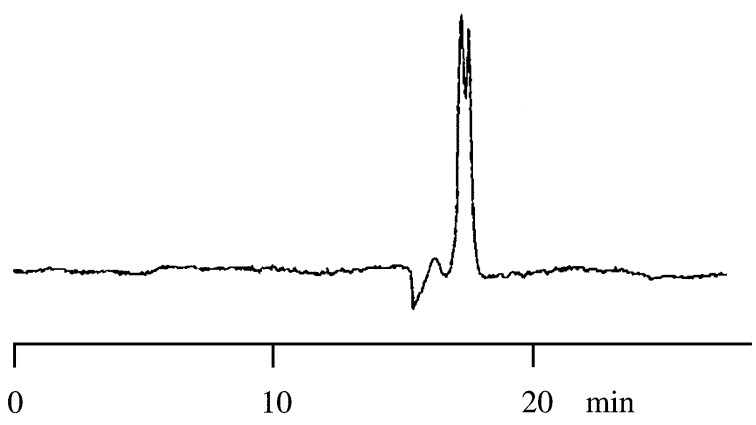

Fig. 2 Separation of enantiomeric N-3,5-dinitrobenzoyl (DNB) phenylalanine isopropyl esters using polymer 2 in electrokinetic capillary chromatography. Conditions: column, fused silica tubing $50 \mathrm{~cm}$ in length (50 $\mu \mathrm{m}$ i.d.); migrating solution, $2 \%(\mathrm{w} / \mathrm{v})$ polymer 2 in $0.05 \mathrm{M}$ phosphate-borate buffer ( $\mathrm{pH} 7.0)$, diluted with $20 \%(\mathrm{v} / \mathrm{v})$ methanol; total applied voltage, about $-24 \mathrm{kV}$; constant electric current, $25 \mu \mathrm{A}$; detection, UV at $254 \mathrm{~nm}$; temperature, ambient. DEnantiomer eluted faster than L-enantiomer.

enhance the separation in EKC, at $T_{0}$ to $T_{\mathrm{m}}$.

Table 2 shows the enantiomeric separation of DNB amino isopropyl esters using a $0.025 \mathrm{M}$ phosphate-borate buffer containing $2 \%(\mathrm{w} / \mathrm{v})$ polymer 2 and diluted with $20 \%$ methanol. The L-enantiomer retention was greater than that of the Denantiomer. The elution order of the amino acid derivatives was according to the amino acid side chain hydrophobicity. However, only a small retention for the alanine derivative was obtained, resulting in no enantiomeric separation. Hydrophobic interactions between polymers and solutes are thus weaker compared to the micelle-like polymers terminated by the Lvaline moiety. ${ }^{8}$ Figure 2 shows a chromatogram for the separation of the phenylalanine derivative. Chiral polymers should form compact aggregates that become entangled; enantiomers separated in water though the action of the valine moiety may incur greater exposure to water than micelle-like polymers.

In a migrating solution of $\mathrm{pH} 9$, the separation window was enhanced. As confirmed by the UV-labeled polymer, however, nearly all solutes moved by electroosmotic flow and the separation capacity was completely lost. At a greater $\mathrm{pH}$ of the migrating solution, the terminal carboxylic acids in the polymers underwent greater dissociation than at $\mathrm{pH} 7$. Adjacent anionic carboxylate groups cause polymer chains to extend, thus lessening the compactness by the electrostatic repulsion, with consequent water penetration into the interior polymer regions. This may possibly be the reason for the elimination of the retention and separation ability at high $\mathrm{pH}$.

Polymer 1 from L-alanine retained solutes to a lesser extent than polymer 2 from L-valine, and thus retained only the most hydrophobic phenylalanine derivative, as evident from the data in Table 3. Polymer 2 should thus form a hydrophobic phase which enables the solute to absorb from bulk water. The hydrophobicity of amino acid residues grafted onto polymer backbones would greatly contribute to the formation of an aggregated and hydrophobic phase. Chiral separation by the Lvaline diamide moiety having greater hydrogen bonding affinity toward solutes than $N$-acyl-L-valine, should be improved. The copolymer $(\mathbf{2}, \mathbf{4})$ containing the L-valine $N^{\prime}$-methylamide exhibited enantiomeric separation, essentially the same as that for polymer $\mathbf{2}$, possibly because the moieties are penetrated by water in a manner similar to that for the L-valine moiety.

Methanol expands the separation window in EKC but may
Table 3 Chiral separation of enantiomeric DNB-phenylalanine isopropyl ester with polymers $\mathbf{1}, \mathbf{2}$ and polymer $(\mathbf{2}, \mathbf{4})$ in electrokinetic capillary chromatography ${ }^{\mathrm{a}}$

\begin{tabular}{|c|c|c|c|c|c|c|}
\hline & \multicolumn{6}{|c|}{ Methanol, \% } \\
\hline & \multicolumn{2}{|c|}{20} & \multicolumn{2}{|c|}{30} & \multicolumn{2}{|c|}{50} \\
\hline & $k_{\mathrm{D}}^{\prime}{ }^{\mathrm{b}}$ & $\alpha$ & $k_{\mathrm{D}}^{\prime}{ }^{\mathrm{b}}$ & $\alpha$ & $k_{\mathrm{D}}^{\prime} \mathrm{b}$ & $\alpha$ \\
\hline Polymer 1 & 0.10 & $1.00^{\mathrm{c}}$ & 0.10 & $1.00^{\mathrm{c}}$ & 0.10 & $1.00^{\circ}$ \\
\hline Polymer 2 & 0.30 & 1.10 & 0.30 & 1.11 & 0.29 & 1.12 \\
\hline Polymer $(\mathbf{2}, \mathbf{4})$ & 0.32 & 1.11 & 0.30 & 1.11 & 0.32 & 1.10 \\
\hline
\end{tabular}

a. Conditions are as described in Table 1 except for migrating solution: $2 \%(\mathrm{w} / \mathrm{v})$ of each polymer in $0.05 \mathrm{M}$ phosphate-borate buffer (pH 7.0), diluted with $20 \%(\mathrm{v} / \mathrm{v})$ methanol.

b. D-Enantiomer eluted faster than L-enantiomer.

c. Enantiomeric separation was not observed.

Table 4 Ratio of emission intensity in $383 \mathrm{~nm}$ and that in 373 $\mathrm{nm}\left(I_{383} / I_{373}\right)$ for pyrene adsorbed into the polymers ${ }^{\mathrm{a}}$

\begin{tabular}{lccccc}
\hline & \multicolumn{3}{c}{$\mathrm{pH} \mathrm{7.0}$} & & $\mathrm{pH} \mathrm{9.0}$ \\
\cline { 2 - 4 } \cline { 2 - 4 } & \multicolumn{4}{c}{ Methanol, \% } \\
\cline { 2 - 4 } & 0 & 30 & 50 & \\
\hline Polymer 1 & 0.51 & 0.53 & 0.54 & & 0.20 \\
Polymer 2 & 0.62 & 0.66 & 0.65 & & 0.31 \\
Polymer (2, 4) & 0.72 & 0.79 & 0.71 & & 0.69 \\
\hline
\end{tabular}

a. Condition: excitation wavelength, $337 \mathrm{~nm} ; 2 \%(\mathrm{w} / \mathrm{v})$ of polymer in $0.05 \mathrm{M}$ phosphate-borate buffer at either $\mathrm{pH} 7.0$ or 9.0 , diluted with various amounts of methanol.

disrupt polymer aggregates by penetration to the interior region. The retention and chiral selectivity for an enantiomer did not change at all in the presence of methanol at up to $50 \%$. The hydrogen-bonding affinity toward solutes is thus shown not to be affected by methanol, even in the case of loose polymer aggregates in methanol-water mixtures.

However, with $1 \mathrm{M}$ urea present in the migrating solution, the solute retention and separation were completely lost. Urea may disrupt the polymer aggregates through elimination of the hydrogen binding network within the polymers.

\section{Evaluation of polymer hydrophobicity in water}

Table 4 shows the ratio of the emission intensity at the 383 $\mathrm{nm}$ band $\left(I_{383}\right)$ to that at the $373 \mathrm{~nm}$ band $\left(I_{373}\right)\left(I_{383} / I_{373}\right)$ for pyrene adsorbed onto polymers $\mathbf{1}, \mathbf{2}$ and polymer $(\mathbf{2}, \mathbf{4})$, and may possibly indicate the polarity of the microscopic environment surrounding pyrene. The intensity ratio of pyrene is 0.5 in water. Under the condition of $\mathrm{pH} 7.0$ without methanol, the intensity ratio for polymer 1 was lowest $(0.51)$ among the polymers investigated in this work.

Although other polymers gave intensity ratios exceeding that for polymer 1, the polar environment appeared virtually to be the same as that provided by water. At $\mathrm{pH}$ values from 7.0 to 9.0 a remarkable decrease was noted in the ratios: from 0.51 to 0.2 for polymer 1 and 0.62 to 0.31 for polymer $\mathbf{2}$, indicating close contact of the dissociated carboxylate anions with pyrene. The decrease, from 0.72 to 0.59 , for the copolymer would partially support this finding in that the copolymer has less terminal carboxylic acid than other polymers. An increase in the $\mathrm{pH}$ must surely destroy the weakly aggregated phase or 
ordinary weak hydrophobic environment of the polymers. A hydrophobicity change with a $\mathrm{pH}$ increase corresponds to the retention change observed in $\mathrm{EKC}$, where a loss of the solutes retention was found at $\mathrm{pH}$ 9.0. No remarkable change in hydrophobicity was observed by a subsequent methanol addition to any polymer. The penetration and adsorption of methanol may eliminate the hydrophobic environment only when the aggregated phase of the polymer has become sufficiently shielded from water.

\section{Conclusion}

We synthesized novel linear polymers grafted with L-amino acid residues that functioned as a chiral pseudostationary phase in EKC. The hydrophobic solute retention was quite weak, but a racemic mixture of 3,5-dinitrobenzoylated amino isopropyl esters could be enantiomerically separated. The observation of pyrene fluorescence indicated no polymer conformed to an explicitly hydrophobic aggregation shielded from bulk water. Although the chiral residues in the polymer may be exposed to water, enantiomeric separation could be effectively carried out despite strong competition from water.

\section{References}

1. S. Terabe, K. Otsuka, K. Ichikawa, A. Tsuchiya, and T.
Ando, Anal. Chem., 1984, 56, 111.

2. S. Terabe, K. Otsuka, and T. Ando, Anal. Chem., 1985, 57, 831.

3. A. Dobashi, T. Ono, S. Hara, and J. Yamaguchi, Anal. Chem., 1989, 61, 1984.

4. A. Dobashi, T. Ono, S. Hara, and J. Yamaguchi, J. Chromatogr., 1989, 480, 413

5. A. Dobashi, M. Hamada, Y. Dobashi, and J. Yamaguchi, Anal. Chem., 1995, 67, 3011 .

6. E. Billiot, S. Thibodeaux, S. A. Shamsi, and I. M. Warner, Anal. Chem., 1999, 71(18), 4044.

7. J. L. Haynes, III, E. J. Billiot, H. H. Yarabe, I. M. Warner, and S. A. Shamsi, Electrophoresis, 2000, 21, 1597.

8. A. Dobashi, M. Hamada, and J. Yamaguchi, Electrophoresis, 2001, 22, 88.

9. H. Ozaki, S. Terabe, and A. Ichihara, J. Chromatogr. A, 1994, 680, 117.

10. P. Blahoslav, C. Emil, M. Beate, T. Eva, K. Ernst, and G. Bohuslav, Anal. Chem., 2000, 72(1), 74

11. B. Potocek, B. Maichel, B. Gas, M. Chiari, and E. Kenndler, J. Chromatogr. A, 1998, 798(1+2), 269.

12. Y. G. Takei, T. Aoki, K. Sanui, N. Ogata, T. Okano, and Y. Sakurai, Bioconjugate Chem., 1993, 4, 42.

13. K. Kalyanasundaram and J. K. Thomas, J. Am. Chem. Soc., 1977, 99, 2039

14. T. Mukaiyama, Syn. Commun., 1972, 2, 243. 